\title{
A Preliminary Study of Culture Shock and Adaptation Tactics for Overseas Chinese Students - from the Perspective of "American Dreams in China"
}

\author{
Zhongjun Xia \\ Guizhou Normal University, Guizhou, 550025, China
}

\begin{abstract}
Culture shock is a common phenomenon in the life of studying abroad. Universally, due to cultural differences in living habits, thinking mode, language level and other fields, Overseas Chinese students may experience four stages of cultural shock, namely euphoria, frustration, adjustment and adaptation, and reverse cultural shock. Each stage will have an impact on their physical and mental health. Therefore, it is necessary for overseas students who want to go abroad to master some countermeasures to adapt to cultural shock, so as to help them spend their overseas study life more smoothly and experience the least negative impact of cultural shock. Based on the cultural shock phenomenon reflected in the film "American dreams in China", this paper discusses the causes of cultural shock for Chinese overseas students and cultural adaptation tactics in intercultural communication.
\end{abstract}

Index Terms —overseas Chinese students, "American dreams in China”, culture shock, adaptation tactics

\section{INTRODUCTION}

Directed by Hong Kong director Peter Chan, "American dreams in China" is a successful and inspiring film of 2013 that tells the story of three young people named Cheng Dongqing, Meng Xiaojun and Wang Yang, who met in college in 1980s and later co-founded an English training school, and finally realized their dreams. This film conveys multiple themes, such as enterprising spirit, warm brotherhood and overseas study heat prevalent in1980s. The role of Meng Xiaojun who wants to realize his ambition in the US reflects the phenomenon of cultural shock in different stages of intercultural communication. Meng Xiaojun is a figure with typical American character and thinking mind which prefers to express his ideas and thoughts directly. However, due to his poor understanding of the actual American culture, he experienced different stages of cultural shock and even frustration in the United States. Based on the analysis of the cultural shock phenomenon embodied in the role of Meng Xiaojun in the film, this paper discusses the cultural shock of overseas Chinese students and their adaptation tactics. This paper discusses the phenomenon of cultural shock experienced by Chinese overseas students on the basis of comparative research method and summary method, and puts forward corresponding adaptation tactics. This paper is divided into three parts. The first part analyzes the phenomenon and causes of culture shock in this film; the second part discusses the countermeasures, and the last part is a summary.

\section{CULTURE SHOCK}

Commonly the culture shock can be divided into intercultural shock and intracultural shock. Intercultural shock stresses on the influence of different cultures or different countries, while intracultural shock refers to the influence of cultural differences between different regions or different nationalities in the same country. The culture shock experienced by overseas Chinese students mainly focuses on intercultural shock.

\section{A. Definition}

Culture shock refers to "the transition period and the accompanying feelings of stress and anxiety a person experiences during the early period upon entering a new culture (Carley, 2006, p. 159)." American anthropologist Oberg (1960) proposed the concept of culture shock and regarded that "cultural shock is caused by the anxiety resulting from losing all our familiar signs and symbols when we move to a new environment in advance (p. 14)." Kalvero Oberg explained the concept of culture shock from the perspective of anthropology and attributed it to the deep psychological anxiety caused by the unfamiliarity with the new social communication signs in the new cultural context. When one comes to a strange culture, he will gradually produce various reactions of culture shock and even more serious physical and psychological rejection, because he is not familiar with social communication symbols and does not adapt to social communication means. Intercultural language is one of the most important symbols of social communication. Language is regarded as the most important communication tool and thinking tool in human social life, as well as the stepping stone of cross-cultural communication. If foreigners fail to learn and use the language of different cultures in a timely 
manner, communication barriers will occur. These setbacks will lead to a sense of cultural deficiency, which may aggravate the negative effects of culture shock.

The above-mentioned scholars mainly attributed culture shock to a psychological disease. While Adler (1975) holds that "paradoxically the more one is capable of experiencing new and different dimensions of human diversity, the more one learns of oneself when a person transcends the boundaries of ego, culture, and thinking (p. 22)." That's to say, we can't explain cultural shock experienced by people outside homelands from a negative perspective solely. Bennett

(1977) put forward the concept of "transitional shock", summing it as "a state where the human organism no longer effectively adapts to the new and changing environment (p. 46)." Initially, transition shock occurs when an figure has experiences of death or divorce with the other half, fails to find relevant or similar reference category in a cross-cultural field, or suffers changes of value or concept caused by rapid social change, etc. Culture shock is exactly a type of transitional shock. To sum up the above points, both psychologically and physically, culture shock has the following major characteristics of impact, such as bitterness, resentment, homesickness, depression etc...

\section{B. Phenomena of Culture Shock}

Culture shock is a common phenomenon in real life. While one person moves to a different culture or stay in a foreign country, he will inevitably be separated from the social network of former life. When one's life environment changes, troubles from the new field such as health-care, material conditions, daily travel or commodities price come one by one, all of that will lead to culture shock indirectly. Some people may adapt to the new environment and lifestyle after a short period of adjustment. Others maybe continue to consider their new environment as a nightmare, rejecting even avoiding contact with new ways of life. In such conditions, overseas people have difficulty integrating into the culture background and society of host countries.

\section{Euphoria Stage}

In the movie, Meng Xiaojun is full of all kinds of yearning for American life before he goes to America. He firmly believes in the American idea that "all people are created equal" and thinks that everything in America is beautiful. In daily life, he is keen on learning everything related to English, dares to show off his English level and ability, and firmly believes that he will study one day in the US. At the beginning of realizing his dream of studying abroad in the United States, he was still graceful and graceful, and found a job as a biology laboratory assistant. Although he was still in high mood and full of ambition, he was full of expectation and expectation for the life in the United States, and believed that coming to the United States was the most correct decision.

This period reflects the euphoria stage of culture shock, which is easily ignored by overseas Chinese students. They may feel fortunate for having the opportunity to move abroad and people overseas are very friendly. They will feel in control similar to pre-departure period. This period is typically characterized by a sense of novelty, excitement maybe last for 2-8 weeks.

\section{Frustration Stage}

After experiencing a period of satisfactory life, Meng Xiaojun's life gradually fell into the dark valley. He gradually lapsed into a period of culture shock. The lab professor recruited a student of biology major to take his place, and his girlfriend left him. Having been working hard, he suddenly felt lost. He could not understand why he was dismissed from such a simple job as feeding mice in the laboratory as a top student. He didn't expect to find a job in America so hard that he would end up working as a waiter in a restaurant. He became demoralized, deeply frustrated and homesick, unable to integrate into American society. All this is precisely because he has not been to the United States before, does not understand the American way of thinking, does not adapt to this fast-paced American life and work crisis.

At this stage, overseas Chinese students may suffer a series of physical problems such as over-caution on cleanliness or diet, strong reaction to not serious diseases. Mentally, students may found that daily frustrations can add up to build into disillusionment easily. Such most difficult phase may last 2-6 months for them.

\section{Adjustment and Adaptation Stage}

In the middle part of the film, Meng Xiaojun begins to understand why he failed, and learns to understand and accept all the difficulties and suffering in the life of studying abroad. He tries to integrate the new culture with his own beliefs. He has the occasional crisis, and develops a positive attitude towards it. Gradually he learned to adjust himself, although it took him a long time. In the later stage of the film, Meng Xiaojun adapted to American culture and American thinking mode, and dared to recall and face up to his own failure. He and his brothers were able to respond methodically, especially when ETS USA prince sued their English training school for copyright infringement. Meng xiaojun's changes in these two stages are the embodiment of adjustment and adaptation.

At this stage, one began to gradually change his behavior and thinking habits, further understand the culture of the other side, and try to adapt to it, so as to effectively cooperate with people in that culture. And he can begin to appreciate a new culture. The most important thing is to be familiar with mutual culture, to be able to identify with two-side culture and integrate into one consequently. Mentally one feels in control and positive again, and has more self-understanding and more tolerance of others and becomes more successful in communications with locals finally. This stage can be also said to have gone through two periods, generally speaking, about 6-12 months.

\section{Re-entry Cultural Shock}

After returning to homeland, he experienced re-entry cultural shock, which is the result from the "psychosomatic and 
psychological consequences of the readjustment process to the primary culture Huff (2001, p. 246).” Deeply influenced by American culture, Meng Xiaojun has encountered various troubles when working with his friends after returning to China. At the beginning of his return to China, his behavior was absolutely different from that of his peers. He even denied his friends' way of thinking and ideas confidently. Just as he could not understand the way of thinking of American local people when he was in the United States, he felt disconnected from life after returning to China. He even could not understand the cultural thinking mode of his native language, which reflected the typical reverse cultural shock. The process of cultural shock experienced by foreign students in different cultures is actually a process of self-change. When you change, your ability to adapt to your original culture will inevitably change. Moreover, when they are studying abroad, the environment of the target language and hometown are also changing to different degrees. Therefore, when they return home, they are surprised even shocked by the enormous changes of former environment, but still regard the experience of studying abroad as very noble. Even they deny the hardships \& difficulties experienced abroad and the beauty of the changes at home. The re-entry period may last one week to three months. The influence is various because of the difference of one's attitude, personality and so on.

\section{Causes Analysis}

Many people choose to study abroad or immigration, and their original intention is to study for further education and broaden their horizons. The behavior itself embodies the courage to take risks and explore new culture. The causes of culture shock are complex and multifaceted. Culture shock occurs not only in the group of international students, but also in the group of immigrants, tourists and business people. There are different opinions on the causes of culture shock in the academic world. Some people consider the conflict and uncertainty between one's native values or rules and those of a new culture lead to one's anxiety and escalate into culture shock later. When a person moves into a new cultural environment, he or she will often feel depressed at the beginning and gradually recover after fully adapting to the new cultural environment. From an individual perspective, the causes of culture shock include age, intrinsic motivation for learning, language ability for destination country, and psychological endurance etc...This paper mainly explains the causes of cultural shock in the following four aspects.

Language communication barrier is the primary cause of cultural shock among overseas Chinese students. Just as the US is a multicultural country full of ethnic groups from various cultural backgrounds. The same sentence or gesture may have completely different meanings among students of varied countries. The collision of different cultures will lead to students' psychological depression over time, and evolve into cultural shock. Lifestyle differences can be said to be the second cause of culture shock. Many Chinese students abroad are not accustomed to the new diet, transportation pattern, law systems, timetable, health-care...etc. For example, some students think daily western food as terrible or traffic as complex. Some students fail to adapt to western culture habits of individualism contrast to former eastern collectivism, which intensifies their loneliness and depression.

Role switching may be the third cause. Many Chinese students are "favored children" or "the apple of parents' eye" at home, but abroad they fail to attract much attention from surrounding people or get ideal grades as normal. As a result, the naturally outgoing and cheerful teenager gradually lives like a lone goose in the flock. On the contrary, many students who are introverted at home have become excellent students and become more popular with surroundings due to the difference between overseas and domestic education systems. Ethnocentrism may be the forth cause of culture shock which refers to comprehend and measure everything in other cultures according to the concepts and standards of their native culture, including people's behaviors, social customs and conventions, management patterns and values and so on. Ethnocentrism as a subjective attitude may be the forth cause for some students, which emphasizes understand and measure everything of exotic cultures according to the concepts and standards of one's own culture (Hu, 1999, p. 183)." In the era of economic globalization and cultural diversity, "each nation needs some emotion to praise the superiority of its own nation in order to unite its internal members, which is a kind of self-culture-centered consciousness or emotions to maintain the positive and creative image of home culture (Hu, 1999, p. 154)." However, once such emotion is over-expressed, it may lead to negative consequences and even conflicts in host countries. Overseas students of each nation love their homelands deeply and are proud of their homelands. Once such emotion exceeds the proper degree will lead to negative effects even cultural conflicts. Without an objective and fair view for other countries and nationalities, the real purpose of studying abroad will not be achieved. Some Chinese students abroad often feel lonely and helpless, think the relationship between people is a little cold. Actually this is because the interpersonal relationship model in western countries is different from that in China. We should not deny such behavior model unilaterally, but objectively understand and accept this model. Ethnocentrism is a universal phenomenon which needs to be controlled to a reasonable degree.

The causes of "re-entry culture shock" can be also explained from three aspects. First, cross-cultural adaptation has been changing people. Long time of living, studying and working in a foreign country will change people's living habits, eating habits, dressing styles, as well as many internal changes, such as values, career views, thinking patterns and so on. Once back in the home culture, these external and internal changes needing certain time to adapt shocked students. Secondly, the region where they live has changed. Living habits formed in a new cultural environment cannot be directly applied to native culture in a short time. People who work, study or live overseas are isolated from each other in space and time, although they have information and Internet to keep in touch with each other. Therefore, the sense of "disconnection" and strangeness will come to people who think domestic everything as normal after returning home. In 
contrast to the enthusiasm and energy before returning home, they finally find that everything is not what they expected any more, and then have to suffer a re-entry cultural shock.

\section{CUltural AdAPTATiOn TACTics}

Cultural adaptation is a dynamic and continuous transmission process opposite to culture shock. Adaptation can be divided into short-term acculturation (mainly individual-oriented) and long-term acculturation (mainly immigrants $\&$ ethnic groups-oriented). Many overseas students often experience different degrees of cultural shock due to their changing roles, differences in lifestyle, language communication barriers, etc. According to Yan (2008), people tend to regard their cross-cultural maladjustment experience as an illness and think that they can only fully devote themselves to other work after the cyclical illness fades away on the negative side. While from a positive perspective, we can find that the process of encountering cultural differences is meaningful and beneficial. People involved in such process can experience and comprehend the impact of cultural shock rather than fix it while getting in trouble. Therefore, it is necessary for overseas students to master certain adaptation tactics to deal with the potential cultural shock positively in overseas life.

\section{A. To Master Cross-cultural Communication Skills}

Paul (1988) considered communication and social-skills as the universal problems involved in the group of overseas students. Before going abroad, students should pay special attention to the knowledge accumulation of target language culture, and learn about foreign culture through various media, such as movie, television and Internet, which is partly an effective way to overcome culture shock. Through the accumulation of target language culture, international students can better distinguish cultural differences, so as to know how to deal with different occasions, time and target language cultural objects, effectively avoid cultural interference in cross-cultural contexts. Due to the communication and collaboration of different cultures content, cross-cultural communication can also help one to examine the advantages and weakness of their own culture.

One's cognitive competence and behavioral competence are the main categories of intercultural communication competence. The cognitive ability in cross-cultural perspective mainly refers to the comprehensive understanding and in-depth understanding of the complexity and diversity of different countries, ethnic cultures in the communication process. Behavioral competence refers to "the ability to deal with various communication problems, including the ability to establish and maintain bilateral relations and the ability to successfully complete communication tasks

(Bradford, 2003, p. 125)." To improve cross-cultural communication ability, on the one hand, students can have cross-cultural training in physics before going abroad and simulate the field situation, so that students can improve their problem-solving ability in the real situation and feel the cultural difference of a foreign country. At the same time, psychological counseling should be given to international students so that they can have a clear understanding of the possible negative effects of cultural shock, and help them prepare for the psychological response in advance.

\section{B. To Cultivate and Strengthen Cultural Empathy Ability}

According to Young (1977), "the time a student spends living in a new culture is proportional to the extent of his or her cultural involvement." When entering the host culture country, international students should get familiar with the living environment around them as soon as possible and communicate with different types of students, especially local students. According to Young (1988), the communication between the students and members of the host culture is conducive to adaptation to a lesser extent. Overseas Chinese students should also participate in local activities and occasions actively to enhance their adaptability. Chen \& Yuan (2008) summarizes cultural empathy as that "the communicative subject consciously changes the cultural standpoint and surpasses native cultural conventions and framework, get rid of the constraints of one's own culture and put himself in another culture mode, so as to truly feel, comprehend and understand another culture (p. 138)." Empathy ability stresses the inclusive degree of various uncertainties in the activities of both sides of cross-cultural communication in terms of emotional psychology. This requires international students to learn to think and express their feelings in the exotic people's standpoint, to empathize with each other through verbal and nonverbal behaviors, and to show that they have fully understood their thoughts and feelings. Students who are new to foreign countries have necessity to keep in touch with their families, exchange study and living conditions, and share local customs and traditions, so as to avoid homesickness. "A positive self-concept is beneficial for students to alleviate self-doubt and allow them to experience new things with less stress (Carley, 2006, p. 162)." In general, those who are optimistic tend to have an advantage in dealing with interpersonal problems and perform better in academic performance. International students should communicate with target language cultural groups such as teachers, classmates and host families in a positive and optimistic attitude, and deal with cultural shock even if they experience it unconsciously. A good state of mind is a prerequisite to avoid worsening the negative effects of culture shock. Jin (1980) stress that "deep involvement in interpreting the host culture in terms of the dominant concepts of the old cultural setting may deny him or her interaction with the first-hand materials of the host society (p. 159)." As much as possible students should try to avoid native cultural consciousness focusing on the national culture, ethics, and the value system of language and culture and so on various aspects superior to any other nation during the overseas life as if they initiate conversations with strangers to keep a certain distance. This kind of behavior will bring 
serious adverse effects on one's life and even cause one to integrate into the target language culture toughly. Students should treat the cultural differences between different countries or ethnic groups in cross-cultural communication with an open inclusive mind and eliminate inner bias for a new culture. Overseas students and native speakers both should hold open, inclusive mind to identify, understand and respect mutual cultural ideas and differences. Cultural conflict and fusion is an objective inseparable fact like the diversity of world culture promoting exchange of various nations. What they need to do is to respect and adapt the differences in cross-cultural communication to minimize shock effects. So when in a different country, just do as the natives of that country. One should rationally cultivate our cultural literacy and adapt to the culture of the host country, and at the same time improve our ability and skills to communicate with each other in cross-cultural communication, so as to avoid culture shock.

\section{To Learn and Integrate Differences of Different Cultures}

Gao (2002) thinks that "eastern culture and western culture, as the two major cultural models of the world culture, basically follow their own unique logic and qualitative stipulations and develop, but they affect and interact with each other (p.118)." Accordingly, if international students want to lessen the shock period or minimize its impact, they have to pay much attention to cultural characteristics and cultural differences of the host country. Different cultures reflect different lifestyles and habits, and naturally there are things by outsiders more or less seen as strengths and weaknesses. Therefore, the evaluation of a culture by people from another field is often limited. For example, the evaluation of the culture of one country by the author in another country is far different from that of the native speakers. Different tourists from country A have different experiences when visiting country B. Therefore, international students should be objective and fair to understand the culture of the host country before going abroad, so as to avoid being affected by one-sided biased comments. When arriving at the host country, they should try best to avoid such stereotype in thinking, so as to take into account the thoughts, feelings, experiences and customs of foreign people in cross-cultural communication. That is to say, international students should master the ability to integrate differences of distinguished cultures. Faced with cultural differences, international students should adopt inclusive attitude and not interpret the language and non-language behaviors of foreign cultures from the perspective of native cultures. Only in this way can they overcome the adverse impacts of varied degrees originated from cultural shock. Only when they treat cultural differences rationally can they integrate into them as soon as possible.

\section{SUMMARY}

Considering the possible impact of culture shock in the future life for overseas Chinese students, students who want to enrich their abroad life should attach great importance to it. Culture shock is not a disease, but a complex and slow process of learning and adaptation. To promote the success of cross-cultural communication, students should strengthen the knowledge accumulation of target language culture, improve cultural sensitivity, adopt an inclusive attitude towards cultural differences and strength cultural empathy. Students should learn about the new culture and integrate differences of exotic cultural filed, improve their linguistic fluency and appropriateness, understand and respect values \& concepts linked to specific behaviors of the host country. As well they have necessity to make acquaintance with close friends to overcome identity stress and loneliness. While falling into culture shock they should keep patient and seek assistance in time so as to avoid experiencing the same severe culture shock as Meng Xiaojun of the movie "American dreams in China". Culture shock may also lead to illness or adverse reactions under relevant circumstances. However, if students can overcome the difficulties and realize the adaptation to the new cultural environment, they will achieve greater self-worth. They can try their utmost to minimize the impact of culture shock although it's unavoidable to suffer culture shock.

\section{REFERENCES}

[1] Adler, PS. (1975). The transitional experience: an alternative view of culture shock. Journal of Humanistic Psychology, 4, $13-23$.

[2] Bennett, J. (1977). Transition shock: Putting culture shock in perspective. International and intercultural communication annual, 4, 45-52.

[3] Bradford, J. H. (2003). Among Cultures: The Challenge of Communication (translated by Ma Zhengqi). Beijing: Communication University of China press.

[4] Chen, E. C \& Yuan, Z. M. (2008). A Study on Cultural Empathy Competence and Intercultural Awareness. Journal of Sichuan International Studies University, 3, 138-140.

[5] Carley, H. D. (2006). Dynamics of Intercultural Communication (Fifth edition). Shanghai: Shanghai Foreign Language Education Press.

[6] Gao, Y. C. (2002). Cultural Integration in Cross-cultural Communication: Value, Methods and Trend. Academic Journal of Suzhou University (Philosophy and Social Science), 2,117-122.

[7] Huff, J. L. (2001). Parental attachment, reverse culture shock, perceived social support, and college adjustment of missionary children. Journal of Psychology \& Theology, 3, 246-264.

[8] Hu, W. Z. (1999). An Introduction to Intercultural Communication (Intercultural Communication Series). Beijing: Foreign Language Teaching and Research Press.

[9] Jin, K. K. (1980). Explaining Acculturation in a Communication Framework: An Empirical Test. Communication Monographs, 
47, $155-79$.

[10] Oberg, K. (1960). Culture Shock: Adjustment to New Cultural Environments. Practical Anthropology, 4, 177-182.

[11] Paul, L. (1988). Communication/Social Difficulty of Thai Students in the Process of Cultural Adaptation. University of Oklahoma.

[12] Young, Y. K. (1977). Inter-Ethnic and Intra-Ethnic Communication: A Study of Korean Immigrants in Chicago. International Communication Annual, 53-68.

[13] Young, Y. K. (1988). Communication and Cross-Cultural Adaptation: An Integrative Theory. Avon \& England: Multilingual Matters.

[14] Yan, W. H. (2008). Cross-Cultural Communication: A Psychological Perspective. Shanghai: Shanghai Academy of Social Science Press.

Zhongjun Xia was born in Jilin, China in 1995. He is currently a postgraduate in the School of Foreign Languages, Guizhou Normal University, Guizhou, China. His research interests include translation theory and practice \& cross-cultural communication. 